\title{
CONTRIBUIÇÕES DA LITERATURA INFANTIL PARA A APRENDIZAGEM DE NOÇÕES DO TEMPO HISTÓRICO: \\ LEITURAS E INDAGAÇÕES
}

\author{
ERNeSTA ZAMBOni \\ Selva Guimarāes FonsecA *
}

\begin{abstract}
RESUMO: O artigo aborda o desenvolvimento das noções do tempo histórico a partir das contribuiçôes da literatura infantil. Como a linguagem literária ficcional, constitutiva do processo de formação da criança, contribui para a aprendizagem da temporalidade histórica nos primeiros anos de escolaridade? As autoras analisam a temática, tendo como referência a leitura de obras literárias, de ampla divulgação no universo da educação escolar brasileira.
\end{abstract}

Palavras-chave: Tempo histórico. Literatura infantil. Aprendizagem.

\section{CONTRIBUTIONS OF CHILDREN'S LITERATURE TO LEARN NOTIONS OF HISTORICAL TIME: READING AND QUESTIONING}

ABSTRACT: This paper approaches the development of notions of historical time based on contributions of children's literature. How can the fiction literature language, which is constitutive of the child formative process, contribute to learn historical temporality in the first grades? The authors analyze the theme having as reference readings of well known literature works in Brazilian school education.

Key words: Historical time. Children's literature. Learning process.

* Doutora em Educação e professora da Faculdade de Educação da Universidade Estadual de Campinas (UnICAMP).E-mail: ernesta.zamboni@terra.com.br

** Doutora em Educação e professora da Faculdade de Educação da Universidade Federal de Uberlândia (UFU).E-mail: selva@ufu.br 


\section{Introdução}

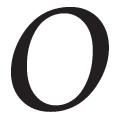

tema deste artigo expressa preocupações, indagações e desejos de refletir sobre conexões entre a literatura e a história no processo educativo. Essa busca, reconhecemos, ocorre num cenário de existência de novas e múltiplas sensibilidades. Os contornos, as margens, os trajetos não lineares das culturas e sociabilidades, cada vez mais fluídas, mobilizam-nos a pensar sobre possibilidades e potencialidades que não se encontram predeterminadas e limitadas pelas fronteiras dos territórios disciplinares.

Reconhecemos que se trata de buscas de potencialidades no diálogo entre a história e a literatura. Esse desvendar implica pensar uma antiga problemática: a relação entre ficção e verdade. O que esses campos do conhecimento (história e literatura) têm em comum? A vida humana e o discurso narrativo. Ambos se preocupam com o cotidiano, com o borbulhar que emana das sensibilidades e paixões presentes nas relações humanas; sensibilidades e paixões presentes no sonho, na utopia, nos afetos, no rememorar, nas lutas de poder. Entretanto, diferenciam-se pelos métodos de construção discursiva, de interpretação, pela preocupação com a verdade, com a objetividade e subjetividades.

A história, o discurso histórico, busca compreender e explicar o real, as verdades sobre fatos, acontecimentos. Por meio do diálogo entre o historiador e as fontes, os documentos, as evidências, é possível a reconstrução do passado. Esse diálogo possibilita ao historiador explicitar o real, os movimentos, a dinâmica da sociedade; propicia a captura das contradições, das mudanças e as permanências na história. O historiador constrói o conhecimento histórico por meio da análise interpretativa e analítica. A literatura, como formação discursiva própria, não concede foros de verdade aquilo que declara (Costa Lima, 1986). A obra literária não tem o compromisso de explicar o real, nem de comprovar acontecimentos. Para interpretá-los, reconstruí-los, o autor recorre à imaginação, à criatividade e à ficção. Isso implica um afastamento do real.

Segundo Sevcenko (1986), a literatura é, antes de qualquer coisa, um produto artístico, porém com raízes no social. Nesse sentido, a literatura pode falar ao historiador sobre a história que não ocorreu, sobre as possibilidades que não vingaram, sobre os planos que não se 
concretizaram. Para o autor, mais do que dar um testemunho, ela revelará momentos de tensão. Assim, o historiador é atraído não pela realidade e sim pela possibilidade.

Tanto na literatura como na história, a narrativa é arte: arte de contar, de pensar, de troca entre sujeitos, de compartir experiências, situações que conheceram e/ou viveram. As narrativas históricas são tratadas sob o viés social, cultural, político. A intenção é clara: demonstrar, a partir de determinados critérios e procedimentos, que o conhecimento histórico é construído por pessoas imersas no seu tempo, capazes de construir problemas, hipóteses e, assim, de contribuir para o estabelecimento de relações entre outros sujeitos, outros acontecimentos e outras temporalidades. O alvo: a formação da consciência histórica.

Nas narrativas literárias, as paixões humanas explicitam a subjetividade do autor. Concordamos com Silva (2009), ao se referir ao discurso literário como produtor de conhecimentos, articulado, segundo alguns fatores, por exemplo, à presença do narrador, ao tempo e ao espaço. Assim, a obra literária ficcional está vinculada ao real vivido. A literatura expressa experiência. E a experiência, segundo Larrosa (2002, p. 26), é "o que nos acontece, nos toca, nos passa, e, ao nos passar, nos forma e nos transforma". Se a experiência, continua o autor, "é o que nos acontece, e se o sujeito da experiência é um território de passagem, então a experiência é uma paixão". Literatura e história são constitutivas da experiência, logo, da formação e da transformação.

Tanto o texto histórico como o literário têm a responsabilidade de "volver inteligibles las herencias acumuladas y las discontinuidades fundadoras que nos han hecho lo que somos" (Chartier, 2008, p. 18). Percebemos, assim, a importância do diálogo entre a literatura, a história e a memória para ampliar o sentido das palavras, ressignificar conceitos, valores, estimular a nossa imaginação para outras realidades, espaços e temporalidades, construir outras percepções do cotidiano, da história local. Enfim, para a (re)construção de identidades.

As relaçôes entre a literatura e a história sempre estiveram presentes na educação. Estão associadas ao desenvolvimento da leitura, da escrita, à percepção dos múltiplos sentidos agregados aos vocábulos, à formação ética e estética, à ampliação do universo cultural e da compreensão de mundo. O domínio da linguagem é fundamental no 
Contribuições da literatura infantil para a aprendizagem de noções do tempo histórico...

processo da comunicação social e nos sensibiliza para a percepção do outro e da realidade que nos cerca. A literatura e a história possibilitam-nos desenvolver a linguagem, fornecem-nos pistas, indícios para a compreensão da realidade, da nossa cultura, da nossa identidade. São mediadoras da/para a aprendizagem humana.

Nessa perspectiva, buscamos, na nossa atuação no ensino, na pesquisa, na formação de professores e produção de textos didáticos e acadêmicos, estimular o interesse dos leitores pela história, pelo desenvolvimento da capacidade de estabelecer relações e conexôes entre fatos, acontecimentos e sujeitos em diferentes temporalidades. Nesse sentido, consideramos pertinente introduzir a criança no "mundo formal" do conhecimento histórico; familiarizá-la com o uso de um vocabulário histórico; despertá-la para a importância das fontes e dos documentos e de conhecer noções, conceitos, suportes modos de construção do conhecimento histórico. Acima de tudo, é fundamental formar, desde cedo, a noção de sujeito histórico: todos nós fazemos história. A criança faz história. Assim, dimensionamos a necessidade do diálogo entre a literatura e a história, pois contribui para a compreensão do poder, da força e dos sentidos das palavras; ajuda-nos a dar sentido ao que somos, ao que nos acontece, estimula-nos a pensar sobre as relaçōes que estabelecemos com nós mesmos, com os outros e com o mundo.

Não podemos deixar de situar esse debate no campo da historiografia, dos estudos literários e da educação. A partir da década de 1980, as contribuições advindas da história cultural potencializaram, valorizaram a presença da literatura no ensino e na pesquisa em História, de forma marcante. A literatura, no ensino de História, passou a ser uma recomendação das propostas curriculares, dos livros didáticos, de projetos pedagógicos em diferentes realidades. Associados às crises e mudanças dos paradigmas, à revisão de valores, ao questionamento de uma visão homogênea, absoluta, na análise dos fenômenos sociais e históricos, vários estudos têm contribuído para a compreensão de modos de aprender e ensinar o tempo histórico. Alguns deles nos inspiram neste texto: Zamboni (1985), Zamboni e De Rossi (2003), Fonseca (2006), Santisteban (2007) e Pagés e Santisteban (2009).

Articuladas a esse conjunto de relações, situam-se as mudanças, as continuidades, nas formas de produção e interpretação do saber histórico escolar. O conceito de tempo histórico deixou de ser considerado 
"unitário", "linear". Nesse contexto de reflexões, nosso objetivo, neste texto, é dialogar com a literatura infantil, refletindo e indagando sobre as contribuições de obras literárias ficcionais para a compreensão do tempo histórico, no processo de ensino e aprendizagem da História nos primeiros anos de escolarização.

\section{Literatura infantil e tempo histórico}

Como a linguagem literária ficcional, constitutiva do processo de formação da criança, contribui para a aprendizagem da temporalidade histórica nos primeiros anos de escolaridade? Esta questão instiga-nos a pensar, a questionar e a nos posicionar ante as relações entre literatura infantil e história. Para explorar essas conexóes, escolhemos dois textos, de ampla divulgação no universo da educação escolar brasileira, de modo específico, nos primeiros anos de escolaridade, que englobam a educação infantil e os anos iniciais do ensino fundamental. Os livros são: Guilherme Augusto Araújo Fernandes, escrito por Mem Fox (2008), e O tempo é feito de muitos tempos, escrito por Murilo Cisalpino (1996).

Por que escolhemos textos cujas temáticas estão relacionadas às noções de tempo histórico e memória? $\mathrm{O}$ universo da literatura infantil é muito amplo e rico em nosso país. Há um grande elenco de obras de autores brasileiros e estrangeiros, disponíveis aos leitores. Não foi fácil proceder a uma escolha, selecionamos vários livros que, no nosso julgamento, possibilitam explorar as dimensões dos conceitos de tempo e espaço; a multiplicidade temporal; a temporalidade da experiência humana; as memórias; as lembranças; a dimensão cultural e social do tempo; enfim, o tempo como reconstrução social, histórica e cultural. Também, foi importante, em nossa escolha, a presença das obras em escolas cujos projetos pedagógicos estimulam o trabalho com narrativas, com a história oral, e, assim, nesse processo, orientam os alunos na recuperação e no registro de memórias de trabalhadores, de pessoas mais velhas e de camadas sociais que, historicamente, foram excluídas da história. Se o conhecimento histórico contribui para entendermos o tempo presente, para nos situarmos na época em que vivemos e termos possibilidades de fazer julgamentos, repudiamos um ensino de História baseado apenas em documentos escritos, oficiais. Nossa defesa é pela (re)construção de práticas de ensino e aprendizagem de História que privilegiem 
Contribuições da literatura infantil para a aprendizagem de noções do tempo histórico...

as narrativas históricas nas quais as paixões humanas, os sentimentos, as contradições, os valores e cotidiano das pessoas comuns estejam presentes e vivos.

O livro Guilherme Augusto Araújo Fernandes foi escrito por Mem Fox, uma professora universitária da área de Literatura Infantil, australiana, autora de livros de literatura para crianças, pais e professores. A ilustradora da obra é Julie Vivas, nascida na Austrália, que viveu sua infância nos Estados Unidos e, depois, na Espanha e Austrália. É um nome presente no meio literário e entre finalistas de prêmios literários na Austrália. Este livro foi publicado, pela primeira vez, em 1984 na Austrália e, no Brasil, em 1995. O titulo original Wilfrid Gordon MacDonald Partridge é o nome completo do pai da autora e o nome do avô (Wilfrid Partridge). A obra já foi publicada em hebraico, espanhol, português, japonês e francês. Segundo o site da autora, só nos EUA já foi vendido mais de um milhão de obras (Fox, 2010, disponível em: http:// www.memfox.com/wilfrid-gordon-mcdonald-partridge.html).

O tema da obra é a memória, mais precisamente, a perda da memória. Segundo a autora, a inspiração e a decisão de escrever o livro ocorreram quando o seu avô viveu em um lar de idosos em North Adelaide. Nas visitas, ela percebia algo que a incomodava: a ausência de crianças. A autora lamenta a separação de idosos e crianças, que se dão tão bem, mas foram isolados uns dos outros pela sociedade. Diante disso, decidiu escrever um livro que tratasse da relação entre crianças e idosos, na esperança de que os professores pudessem estimular o contato intergeracional.

A narrativa se desenrola em torno das memórias compartidas pelo menino chamado Guilherme Augusto Araújo Fernandes e a senhora Antônia Maria Diniz Cordeiro. Ele morava com a sua família próximo a um asilo de velhos. O menino gostava de conversar com as pessoas que lá viviam, conhecia os seus nomes, os seus fazeres, ouvia as suas histórias. Estar no asilo estimulava a sua imaginação. Havia aquela que tocava piano, outro remava, outro andava com bengala, outros gostavam de contar histórias. Entre todas as pessoas que lá moravam, havia uma senhora que lhe contava todos os seus segredos. E existia entre eles uma cumplicidade, ambos possuíam quatro nomes. Certa vez, Guilherme Augusto ouviu os seus pais comentarem que a senhora Antônia tinha perdido a memória. Ele ficou angustiado e questionou: 
o que é memória? Perguntou para cada uma das pessoas do asilo o que era a memória. Disseram-lhe que era "algo quente", "bem antigo", algo que "faz chorar", "faz rir", "vale ouro". Resposta alguma foi simples, objetiva; estavam relacionadas à vida de cada um deles, àquilo que lhes passava na alma e no coração. Foram respostas, aparentemente, simples, mas profundamente subjetivas. $\mathrm{O}$ menino ficou mais angustiado: o que fazer? Ele voltou para casa com as respostas e com o desejo de procurar memórias para Dona Antônia, já que ela havia perdido as suas.

Guilherme Augusto, curioso, preocupado em encontrar uma memória para a sua amiga, procurou, em sua casa, objetos que poderiam auxiliá-lo. Com as palavras que lhe pareciam incógnitas: antigo, rir, chorar, quente, ouro, começou a buscar os primeiros indícios em uma velha caixa de sapato, cheia de conchas. É sugestivo, instigante, pensar que os seus primeiros passos se deram a partir de conchas. A concha, simbolicamente, representa o útero materno, no seu interior forma-se a pérola. Para o menino, a "pérola" foi o início para a formação ou reconstituição da memória. Desde esse momento, ele encontrou vários objetos do seu cotidiano e os selecionou, tendo como critério as palavras que representavam o "enigma" da memória (marionete/riso; medalha/tristeza; bola/ouro; ovo/quente).

A (re)construção da memória relaciona-se ao trabalho com os objetos do cotidiano, que pertencem ao tempo vivido. Segundo Bosi (2003, p. 26), "quanto mais voltados ao uso do cotidiano, mais expressivos são os objetos: os metais se arredondam, se ovalam, os cabos de madeira brilham pelo contato com as mãos, tudo perde as arestas e se abranda”. A autora nos lembra Violette Morin, ao denominar esses objetos

(...) de objetos biográficos, pois envelhecem com o possuidor e se incorporam à sua vida: o relógio da família, o álbum de fotografias, a medalha do esportista, a máscara do etnólogo, o mapa-múndi do viajante... Cada um desses objetos representa uma experiência vivida, uma aventura afetiva do morador. Só o objeto biográfico é insubstituível: as coisas que envelhecem conosco nos dão a pacífica sensação de continuidade. (Idem, ibid.)

Feliz, Guilherme deu a Dona Antonia cada um dos objetos, e ela começou a se lembrar. No contato com cada um deles, contou-lhe 
um fato marcante da sua vida. Assim, ela (re)encontrou a sua memória. O procedimento de Guilherme Augusto nos remete ao inspirador texto de Bosi (op. cit., p. 53), quando afirma: "A memória é, sim, um trabalho sobre o tempo, mas sobre o tempo vivido, conotado pela cultura e pelo indivíduo". A memória está nos objetos do cotidiano, cada um deles tem uma história, um sentido para o indivíduo.

O texto de Fox nos remete ao trabalho com a memória, no entrelaçar dos fios entre o presente (a criança, os objetos do cotidiano) e o passado (as lembranças, os "segredos", seus tempos de criança, outros objetos, seus familiares). A memória é como se fora uma mediadora entre as geraçóes, entre o passado e o presente, entre o presente e os testemunhos passados. Os objetos, como elementos informais da cultura, possuem historicidades. E o contato com cada um destes objetos permite-nos reconstruir comportamentos, acontecimentos e sensibilidades de uma época - que nos impelem a pensar nas temporalidades. Para Leopoldo e Silva (2010, p. 3),

(...) o caráter mais geral da temporalidade é ser histórica, e por isso se trata de uma experiência moldada por condições sociais, econômicas, culturais e materiais. Por isso a experiência do tempo não pode ser a mesma numa sociedade feudal e numa sociedade capitalista; num mundo em que prevaleça a estrutura agrária e naquele já definido pela industrialização; em países mais ou menos urbanizados; em lugares em que a vida material cotidiana ainda se rege por padrôes tradicionais e naqueles em que a tecnologia já está consolidada.

Isso nos ajuda a entender, segundo o autor, como as condições subjetivas e objetivas se relacionam nas diferentes formas históricas de experiência do tempo.

O livro O tempo é feito de muitos tempos foi escrito por Murilo Cisalpino, mineiro de Belo Horizonte, professor de História, autor de livros para crianças, jovens e adultos. Foi ilustrado por Marcelo Eduardo Lélis de Oliveira, também mineiro, nascido em Montes Claros, norte de Minas, onde viveu até 1992, quando foi para Belo Horizonte trabalhar como chargista e ilustrador. Recebeu vários prêmios e passou a dividir seu tempo entre a capital mineira e a cidade de São Paulo.

A narrativa é construída em torno da relação entre o avô e o neto chamado Mundinho. A palavra "pedra de toque" da história; a pergunta, a indagação inicial de Mundinho, irritado, ao seu avô é "alpendre": 
nome gostoso de varanda, varanda recheada de histórias, explica o avô, que lamenta o fato de, hoje, não termos mais nem alpendres, nem varandas, mas apenas umas sacadinhas por aí... A irritação de Mundinho tinha uma razão: usara esta palavra "do avô" em uma redação na escola e fora zombado pelos colegas que lhe disseram que ele era do "tempo dos calhambeques". O avô o consolou, explicando-lhe que o importante era que conhecesse as histórias, como a de calhambeques. Assim descobriria que "o tempo é feito de muitos tempos". O diálogo em torno das palavras nos lembrou Larrosa (2002), quando alerta sobre o poder e a força das palavras, pois fazemos coisas com as palavras e as palavras também fazem coisas conosco, afirma. Pensamos (dar sentido ao que somos e ao que nos acontece) a partir de nossas palavras e o "sentido e o sem-sentido é algo que tem a ver com as palavras” (p. 21).

Após esse diálogo sobre o "alpendre", Mundinho e seu avô (imbuído do desejo de narrar histórias) saem de casa, andam pelas ruas da cidade grande onde moram, calados, observando o espaço, as construções, o ambiente, o movimento das pessoas, os bichinhos na praça; quando, então, o avô começa a lhe contar sobre a vilazinha de uma única rua, onde nasceu e viveu a sua infância. Falou dos lugares da cidadezinha do interior, da natureza, das pessoas, da professora, os amigos, a pescaria (quando pegou o peixão), dos objetos, festas, comidas, costumes da vida no interior. Até que um dia... chegou à vilazinha "uma coisa de outro planeta”: um caminhão moderno, bonito, reluzente. $\mathrm{O}$ motorista do caminhão, ao perceber o encantamento do jovem, contou-lhe sobre a cidade grande. Tal foi o fascínio que resolveu ir embora (contrariando a vontade dos pais) e conhecer a tal cidade grande na companhia do motorista. Neste momento da narrativa, o avô faz uma pausa, se perde em suas lembranças para, então, recomeçar a contar a história de sua vida no outro lugar. $\mathrm{Na}$ cidade grande, ele trabalhou, aprendeu a arte de pintar faixas, cartazes, letreiros. Chamou a atenção do neto para o banco em que estavam sentados naquela praça. Foi pintado por ele anos atrás. $\mathrm{O}$ menino passa a imaginar o avô jovem, pintando bancos. Como seria seu avô? Como se vestia? Como era ele? Imagina Mundinho... $\mathrm{Na}$ última parte da narrativa, os dois voltam a caminhar de volta para casa, enquanto o avô descreve o bairro no seu tempo de juventude. O comércio, as construções, as casas. Conta-lhe muitas coisas e como foi que construiu a casa deles, com a ajuda dos amigos, por meio de um mutirão. Os dois retornam a casa, sobem a 
Contribuições da literatura infantil para a aprendizagem de noções do tempo histórico...

escada até o alpendre (a varandinha), e o garoto interroga: "Vô, como é que se chamava o motorista do caminhão?". O avô responde: "Everaldo". O menino repete: "Everaldo, como o meu pai" (Cisalpino, 1996, p. 18).

A história é extremamente rica em detalhes sobre os lugares, as situações, os contrastes, as diferenças, as semelhanças, as permanências e continuidades na história. Fala-nos do tempo humano, uma construção sociocultural e histórica, múltipla e plural. Instiga-nos a reflexão sobre as condiçốes de vida dos brasileiros, nas pequenas e grandes cidades, de modo particular daqueles que migraram do interior para as cidades grandes. $\mathrm{O}$ texto instiga-nos sobre os modos de viver o tempo. Sobre isso, Leopoldo e Silva (2010, p. 3) argumenta:

(...) é evidente que as condições materiais ligadas ao avanço da tecnologia (transporte, comunicação, trabalho, lazer, vida social e doméstica) determinam em larga medida a vivência da temporalidade na sociedade contemporânea. Tais condições determinam hábitos e uma mentalidade geral que resultam em modos específicos de viver o tempo. O impacto cultural dessas condições aparece nitidamente nos primeiros momentos de sua incidência, nos ambientes ainda configurados pela tradição, isto é, por outras formas de viver o tempo, que vão sendo substituídas, de modo mais ou menos natural e/ou mais ou menos traumático, até que uma nova organização temporal da vida seja, completamente, introjetada e assumida como natural pelos indivíduos e grupos.

O avô lembra o impacto do "caminhão", uma coisa de outro mundo, que mexeu, desestabilizou seu cotidiano, seu viver. O caminhão simboliza seu "transporte", seu "passaporte" para outro mundo (lugar) e outro tempo (o futuro). O mundo da cidade grande, da aprendizagem da profissão, da construção de uma casa, de uma família. A passagem da juventude para a vida adulta. O motorista é o mediador, o condutor, o "responsável" pela mudança, aquele que o introduz e o apóia (ele morou na casa do motorista) em outra temporalidade. Tal é o protagonismo do motorista do caminhão na história de vida do avô que o filho recebe o seu nome, "Everaldo", e o neto Mundinho, ao reconstruir os fios da memória, compreende o sentido daquele gesto.

As memórias reconstruídas pelo avô em diálogo com o neto expressam de forma sensível como tempo e espaço, como construções sociais, são inbricados, entrecruzados. Nesse sentido, Vinão Frago (1996, p. 62) assegura que: 
(...) la noción del tiempo y de la duración nos llegan a través del recuerdo de espacios diversos o de fijaciones diferentes en un mismo espacio. De espacios materiales, visualizables (...). Esta aprehensión del espacio vivido es un elemento determinante en la conformación de la personalidad y mentalidad de los individuos y dos los grupos.

O espaço comunica, conserva memórias, vestígios, elementos culturais, histórias. Espaço e tempo não são neutros, configuram e evidenciam relações de poder, vivências, processos. Logo, chamam a si diversas percepções, interpretações e representações.

Os dois textos abordam as relações intergeracionais (crianças e idosos), mediadas pela memória. O tempo humano, múltiplo e plural, em (re)construção. Para Viñao Frago (op. cit.), essa pluralidade tem uma estreita relação com a linguagem e não se trata apenas de uma pluralidade intercultural, mas também intracultural. Cada sociedade constrói estruturas, relações próprias de tempos diversos. Nuances da linguagem dos idosos e das crianças no diálogo presente/passado são abordadas com delicadeza nas duas narrativas. Preti (1991, p. 28), ao analisar a linguagem dos idosos, conclui que:

(...) sob o aspecto conversacional, revela-se a importância da categoria tempo e a presença constante do passado, como o ponto de referência constante para o discurso que, ainda quando centrado em temas do presente, se articula com base em duas realidades, a do ontem e a do hoje.

Vamos relembrar duas palavras: "memória e alpendre". As leituras e o diálogo com as narrativas motivam a comunicabilidade, a interação entre crianças e idosos, e, assim, podem atenuar o sentimento de frustração, o isolamento, a solidão e aquilo que Preti (op. cit., p. 29) constatou entre os idosos: "a linguagem do... silêncio".

As duas narrativas podem contribuir de forma significativa para o ensino e a aprendizagem do tempo histórico nos primeiros anos de escolaridade, permitindo-nos focalizar, de forma criativa e sensível, as múltiplas maneiras de viver e representar o tempo, os diversos modos de fazer e interpretar a história. Esse processo é fundamental para a construção da memória histórica e da consciência histórica. Concordando com Pagés e Santisteban (2009, p. 203-204):

(...) la memoria histórica y la consciencia histórica tienen una importante función cultural: forman y expresan identidad. Delimitan el reino de la 
propia vida, de la familia, nuestro mundo frente al mundo de otros, que es generalmente un mundo extraño (...). Realizan esta función en una perspectiva temporal, el cambio temporal de los seres humanos y de su mundo, de sus experiencias (...).

As narrativas literárias endereçadas às crianças, como produtos culturais de um tempo histórico marcado pelo acelerado desenvolvimento tecnológico dos meios de informação, articuladas a outras produçôes visuais, textuais, às fontes orais, constituem ricas bases de significações das tramas das experiências humanas nos diversos tempos e espaços. Logo, são estímulos para a reflexão sobre a formação, a educação das novas gerações. Pensar a leitura como formação implica pensála, segundo Larrosa (1996, p. 16), como uma atividade que tem a ver com a subjetividade do leitor: "Se trata de pensar a lectura como algo que nos forma (o nos de-forma o nos trans-forma), como algo que nos constituye o nos pone cuestión en aquello que somos”. Assim, a leitura literária mesclada, entrecruzada com as narrativas históricas, não pode ser reduzida a um meio de adquirir conhecimentos, mas com uma atividade que "tiene que ver com aquello que nos hace ser lo que somos" (idem, ibid.).

\section{Algumas indagações}

A aprendizagem do tempo histórico, assim como a formação do aluno/cidadão, não é tarefa exclusiva da educação escolar. Trata-se de um processo que se inicia e se processa ao longo da vida, nos diversos espaços. Acreditamos que o professor, ao ensinar História, incorpora as noções transmitidas no processo de socialização da criança, no mundo vivido fora da escola, na família, nos espaços de lazer, no diversos ambientes sociais e educativos etc. Nesse sentido, cada vez mais, são ampliados e difundidos projetos pedagógicos que focalizam o uso de diversificadas fontes e linguagens no processo de ensino e aprendizagem, na educação infantil e anos iniciais do ensino fundamental.

Uma indagação recorrente entre nós educadores é: como ensinar? Como aprender o tempo histórico? As buscas de respostas nos conduzem à defesa do trabalho educativo inter e transdisciplinar em História. Este trabalho ganha especial significado no interior do processo de alfabetização linguística, temporal e espacial da criança. Isto 
nos leva a outra indagação ainda recorrente no meio escolar: é necessário primeiro alfabetizar a criança (ensinar a ler e escrever no sentido restrito) para depois ensinar História? Como ensinar história para crianças que ainda não dominam a leitura e a escrita? Por que não ousar uma resposta, fazendo outra pergunta: é possível alfabetizar sem a História? A proposta é alfabetizar ensinando e aprendendo História (Fonseca, 2009).

O trabalho pedagógico com textos literários nas aulas de História pode oferecer-nos pistas, referências sobre o modo de ser, viver e agir das pessoas, os valores, os costumes, histórias de uma determinada época, de determinados grupos. Estas obras são fontes, evidências que nos auxiliam a desvendar e compreender a realidade, as mudanças menos perceptíveis, detalhes sobre lugares, ambientes, paisagens, culturas, modos de vestir-se, enfim, detalhes de uma época. As duas obras são exemplares. Como nos ensina Bosi (2003, p. 19): “(...) a narrativa mostra a complexidade do acontecimento. É a via privilegiada para chegar até o ponto de articulação da história com a vida cotidiana. Colhe pontos de vista diversos, às vezes opostos, é uma recomposição constante dos dados".

Outra indagação presente no campo do ensino de História é sobre os limites dos diferentes tipos de textos, as fronteiras entre o discurso histórico e ficcional. Como não usar a literatura infantil como meros complementos ou ilustração? Acreditamos que a literatura infantil constitui uma fonte extremamente rica a ser problematizada pelo professor, que, por meio de um trabalho interdisciplinar, promoverá o acesso do aluno a outras linguagens, outras histórias, e o desenvolvimento de posturas críticas e criativas. Acreditamos que podemos enriquecer o processo de alfabetização e ampliar a aprendizagem histórica num processo de diálogo, aberto, livre e sensível entre memória, tempo, história. Como nos ensina Bosi (op. cit., p. 53):

A memória é, sim, um trabalho sobre o tempo, mas sobre o tempo vivido, conotado pela cultura e pelo indivíduo (...). É verdade, porém, que nossos ritmos temporais foram subjugados pela sociedade industrial, que dobrou o tempo a seu ritmo, "racionalizando" as horas de vida. É o tempo da mercadoria na consciência humana, esmagando o tempo da amizade, o familiar, o religioso. A memória os reconquista na medida em que é um trabalho sobre o tempo, abarcando também esses tempos marginais e perdidos na vertigem mercantil. 
Guilherme Augusto Araújo Fernandes e Mundinho nos ensinam que é possível reconquistar tempos perdidos, marginais, esquecidos e, assim, tornar mais humano esse nosso tempo que separa, exclui, silencia...

Recebido em junho de 2009 e aprovado em novembro de 2009.

\section{Referências}

BOSI, E. O tempo vivo da memória - Ensaios de psicologia social. São Paulo: Ateliê Editorial, 2003.

CHARTIER, R. Escuchar a los muertos con los ojos. Buenos Aires: Katz Editores, 2008.

COSTA LIMA, Luiz. Sociedade e Discurso Ficcional. Rio de Janeiro: Guanabara, 1986.

CISAlPINO, M. O tempo é feito de muitos tempos. Belo Horizonte: Formato Editorial, 1996.

FONSECA, S.G. Didática e prática de ensino de História. 5. ed. Campinas: Papirus, 2006.

FONSECA, S.G. É possível alfabetizar sem História? Ou... como ensinar História alfabetizando. In: FonseCA, S.G. Ensino fundamental: conteúdos, metodologias e práticas. Campinas: Alínea, 2009. p. 241-266.

FOX, M. Guilherme Augusto Araújo Fernandes. Trad. Gilda Aquino. São Paulo: Brinque-Book, 1995.

LARROSA, J. Notas sobre a experiência e o saber da experiência. Revista Brasileira de Educação, Rio de Janeiro, n. 19, p. 20-28, 2002.

LARROSA, J. La experiencia de la lectura - estudios sobre literatura y formación. Barcelona: Laertes, 1996.

LEOPOLDO E SILVA, F. A experiência do tempo. Disponível em: <http://www.sescsp.org.br/sesc/revistas/>. Acesso em: 5 jun. 2010.

LIMA, L.C. Documentação e ficção. In: Lima, L.C. Sociedade e discurso ficcional. Rio de Janeiro: Guanabara, 1986. p. 187-42. 
PAGÉS, J.; SANTISTEBAN, A.F. Câmbios e continuidades - aprender la temporalidade histórica. In: FONSECA, S.G. Ensino fundamental: conteúdos, metodologias e práticas. Campinas: Alínea, 2009. p. 197-240.

PRETI, D. A linguagem dos idosos. São Paulo: Contexto, 1991.

SANTISTEBAN, A.F. Una investigación sobre cómo se aprende a enseñar el tiempo histórico. Enseñanza de las Ciencias Sociales, Barcelona, n. 6, p. 19-29, 2007.

SEVCENKO, N. Literatura como missão. São Paulo: Brasiliense, 1986.

SILVA, M.Q.V. Discurso literário, função poética e literatura infantojuvenil

um olhar sobre a construção do conhecimento em Bartolomeu Campos de Queirós. Disponível em: <http://www.filologia.org.br/ixcnlf/17/ 26.htm>. Acesso em: 8 nov. 2009.

VIÑAO FRAGO, A. Espacio e tiempo, educação e história. Morelia: IMCED, 1996.

ZAMBONI, E.; DE ROSSI, V.L.S. (Org.). Quanto tempo o tempo tem?. Campinas: Alínea, 2003.

ZAMBONI, E. O desenvolvimento das noções de espaço e tempo na criança. Cadernos CEDES, Campinas, n. 10, p. 63-71, 1985. 